\title{
HOMEOSTASIS
}

\section{The Ancient Greek Origin of a Modern Scientific Principle}

\author{
Theano D. Kontopoulou, Spyros G. Marketos
}

International Hippocratic Foundation of Kos, Greece

\section{INTRODUCTION}

Many medical terms have a long history ${ }^{1}$. They are first introduced as a concept and later acquire their proper name. In this article we trace the origin of the term homeostasis, which in modern medicine means the complex balance and the constancy of all aspects of body function and the coordinated regulation of its component fluids and cells. The various organs and systems have different roles in the maintenance and stability of the composition of the internal environment.

\section{ETYMOLOGY}

The term homeostasis, which belongs to the linguistic treasure of the Greek language, derives from the words

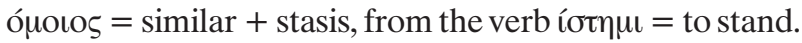

\section{ANCIENT ROOTS}

The distant roots of the term homeostasis go back to Greek antiquity, namely to pre-Socratic philosophy ${ }^{2,3}$ and to Hippocratic medicine ${ }^{4}$. Early natural philosophers from the west coast of Asia Minor, southern Italy and Sicily, sought to explain the universe by pure reason. Alcmaeon of Croton introduced the term isonomia. His

Key words: Homeostasis, Pre-Socratic philosophy, Hippocratic medicine, history of medicine, endocrine terminology.

Address correspondence and requests for reprints to: SG Marketos, 20 P. Ioakim Str., 10675 Athens, Greece, Fax: 0103642197 - 010724 6162, Tel: 0107219534 - 0103601378

Received 20-01-02, Revised 08-02-02, Accepted 28-02-02 doctrine concerning the balancing of opposite qualities seems to be the distant ancestor of homeostasis. Empedocles of Agrigentum proposed that the entire universe consists of four basic elements (= rhizomata or racins): earth, water, air and fire. The combination of the four components expresses a logos (or formula) that is specific for each individual and for each tissue or organ of living beings. The Empedoclean doctrine concerning the fusion of the four dissimilar elements is regarded as the precursor of the Hippocratic humoral system (Figure 1).

\section{HUMORAL THEORY}

Hippocrates combined the 6th century $\mathrm{BC}$ achievements of the philosophers of Asia Minor with Pythago-

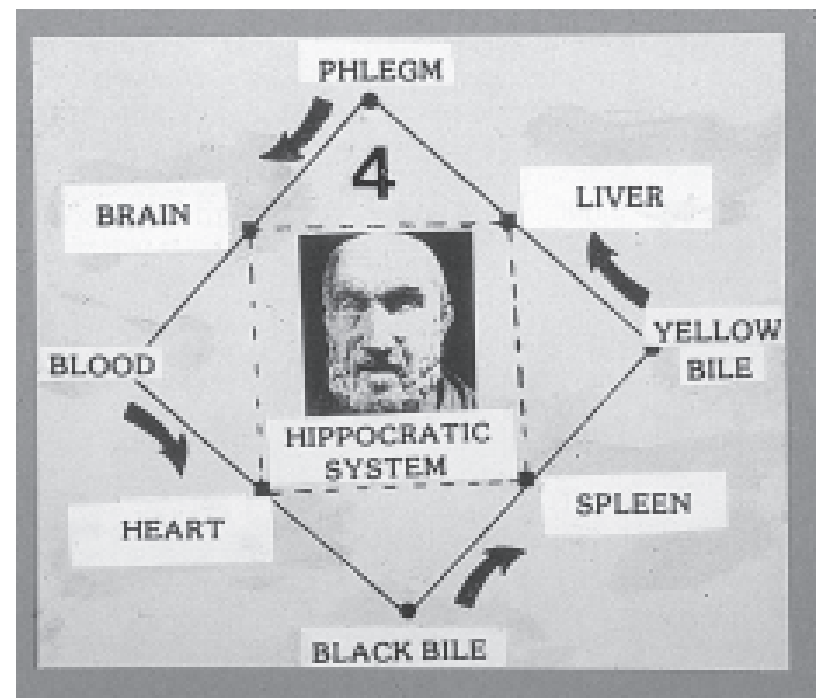

Figure 1. Hippocratic Humoral System 
ras/ theory, his pupil Alcmaeon's percepts and Empedocles' concepts about the equilibrium of dissimilar elements and of opposite qualities, thus developing the humoral theory for human physiology (Figure 1). According to this theory, human beings consist of a soul and a body, which contain four humors: blood, phlegm, black and yellow bile, that correspond to the four organs of the body: the heart, the brain, the liver and the spleen. These four humors are in continuous motion through the circulation. The equilibrium (the balance) and the harmony of the four humors (eucrasia in Greek terminology), is identified with health. Their disequilibrium (the imbalance) and disharmony (dyscrasia in Greek terminology) produces disease ${ }^{5}$.

\section{MODERN CONCEPTS}

Claude Bernard, the founder of Experimental Physiology, first recognized as a consept the significance of the body's "milieu interieur" (internal environment) ${ }^{6,7}$ which in the organisms of higher animals is kept constant (homeostasis) through several interacting mechanisms. According to this great concept, various biological constants resist any external factors which tend to alter the stability of the composition of the internal environment.

Walter Bradford Cannon, the famous Harvard physiologist, proposed to call this state of stability homeostasis $(1932)^{8}$ Since then, this Greek term is widely used and the phenomenon described is accepted as one of the fundamental principles of physiology.

\section{CONCLUSIONS}

The modern scientific principle of homeostasis (1932) has roots extending back to pre-Socratic natural philosophy and to Hippocratic medicine. The etymology of this term reflects the marvelous evolution of science and its linguistic expression over time.

\section{REFERENCES}

1. Poulakou-Rebekakou E, Marketos SG, 2002. Endocrine Terminology in Corpus Hippocraticum. Hormones 1 (1): 57-58.

2. Kizk GS, Raven JE 1983. The pre-Socratic Philosophers. Cmbridge, M. Schofield.

3. Longriff J., 1993, Greek Rational Medicine: Philosophy and Medicine

4. Longriff J., 1989. pre-Socratic philosophy and Hippocratic medicine. Hist. Science 27: 1-39

5. Marketos SG, 1997. The medical school of Kos, Hippocratic Medicine. Forum Trends in Experimental and Clinical Medicine 7: 313-324.

6. Bernard Cl., 1856. Lecons de Physiologie Experimental Appliquee a la Medicine. Paris, JB Bailliere.

7. Bernard Cl., 1878. Lecons sur les Phenomenes de la Vie. Paris, JB Bailliere.

8. Cannon WB, 1932. The Wisdom of the Body. New York: W.W. Norton and Company. 